\title{
Capturing quantitative zooplankton information in the sea: Performance test of laser optical plankton counter and video plankton recorder in a Calanus finmarchicus dominated summer situation
}

\author{
Sünnje L. Basedow ${ }^{a, b, *}$, Kurt S. Tande ${ }^{b}$, M. Fredrika Norrbin ${ }^{a}$, Stian A. Kristiansen $^{a}$ \\ a Department of Aquatic Biosciences; Faculty of Biosciences, Fisheries and Economics; University of Troms $\varnothing, \mathrm{N}-$ \\ 9037 Troms $\varnothing$, Norway \\ ${ }^{\mathrm{b}}$ Faculty of Biosciences and Aquaculture, University of Nordland, N-8049 Bodø, Norway \\ *: Corresponding author : Sünnje L. Basedow, tel.: +47 75517586 ; fax: +47 75517457 ; \\ email address : sunnje.basedow@uin.no
}

\begin{abstract}
:
We compared two optical plankton counters, the Laser Optical Plankton Counter (LOPC) and the Video Plankton Recorder (VPR) for their abundance estimates of Calanus finmarchicus during an early summer situation (June 2008) in two North Norwegian fjords. The LOPC was mounted on the VPR frame in order to sample the same body of water. The combined system of LOPC and VPR was operated by vertical profiling from the surface to $100 \mathrm{~m}$ of depth in several locations of the fjords representing different blooming conditions and zooplankton community structures. Data from the two instruments, as well as from CTD-F, were logged concurrently and retrieved on deck after about 15 depth profiles. Primary data were analysed according to standard routines, and choices made during sampling and analyses (sampling volume, selection of size range, transparency of particles, statistics) are discussed. Data were averaged for every 5,10 and $15 \mathrm{~m}$ depth bins. The vertical profiles of $C$. finmarchicus CIV-CVI abundance that were obtained by LOPC and VPR, respectively, showed a striking similarity. No significant differences between profiles sampled by these two instruments were observed when data were binned into $15 \mathrm{~m}$ bins. At low abundances $\left(<100\right.$ Calanus sp. $\left.\mathrm{L}^{-1}\right)$ profiles were significantly different when data were binned into $5-$ or $10-\mathrm{m}$ bins. This is attributed to the small sampling volumes of the LOPC and the VPR, and to very patchy distributions of copepods, resulting in a high standard deviation between consecutive profiles. Based on the results we conclude that the time is mature for a more extensive use of optical instruments to estimate zooplankton abundances and distributions in the sea.
\end{abstract}

\section{Highlights}

Laser optical plankton counter and video plankton recorder were compared. Calanus abundance estimates in $15 \mathrm{~m}$ depth bins did not differ between instruments. The vertical distribution patterns observed by LOPC and VPR agreed very well. - The VPR estimated ca. 2.4 times higher abundance than the LOPC. Variance between consecutive vertical profiles was higher than between instruments. 


\section{${ }_{21} 1$ Introduction}

Automated and semi-automated sampling of zooplankton has been sought for a long time as part of a modern approach to map the marine environment. The need for sensors capable to deliver abundance and biomass data with a high resolution in space and time has generated an increasing effort to bridge the gap between different contemporary sampling methods in marine science. The Optical Plankton Counter (OPC) was one response to this challenge. It was designed to provide continuous real-time information on the size and abundance of zooplankton (Herman 1988; Herman et al. 1993). The OPC has since been carried on many different platforms, and has been successfully applied in numerous oceanographic studies (Herman et al. 2004, and references therein). A special effort has been made to build confidence in the use of the OPC towards estimating abundance of one of the most important zooplankton genera in the North Atlantic, Calanus spp. (Heath 1995; Heath et al. 1999; Baumgartner 2003). Abundance estimation of older stages of Calanus spp. has been highly successful, except that at extremely high abundances the OPC has problems to accurately separate between particles, and it then counts multiple particles as one. These so-called coincidence counts lead to an underestimation of abundance, but an overestimation of the size of particles (Osgood and Checkley 1997; Sprules et al. 1998). The Laser-OPC (LOPC) was introduced as the second generation of the OPC in the beginning of the new millennium to provide broader ranges in sizes and abundance estimates than the OPC, and also to provide information on the morphology of zooplankton (Herman et al. 2004). Recently, the LOPC has successfully been used to assess copepod abundance and size structures in deep water overwintering habitats (Gaardsted et al. 2010). The LOPC has also provided data to analyse processes within mesozooplankton communities based on biovolume spectra (Basedow et al. 2010), but its potential as a diagnostic tool in surface waters during summer remains to be established.

The Video Plankton Recorder (VPR) was developed in the early 1990s, and the current models have replaced analog video recording with digital technology (Davis et al. 1992, 2005). The VPR has been especially useful for comparing taxonomic composition and distributions of plankton taxa along the depth axis and in different geographical 
regions (e.g. Gallager et al. 1996; Norrbin et al. 2009). Currently two VPR models are in use: a larger system that requires an advanced winch and fiberoptic cable but is capable of collecting data in real-time on research vessels going at a speed of up to $10 \mathrm{knots}$, and a simpler autonomous system (digital AVPR) of which data will be downloaded after deployments. Today the VPR routinely provides data on plankton distributions with high resolution and sample density (Gallager et al. 1996; Ashjian et al. 2001, 2008). With the development of automated identification techniques for image processing, the larger system is now capable of analysing zooplankton distributions in near-real-time at sea (Davis et al. 2005; Hu and Davis 2005). In a recent study comparing zooplankton abundance estimates by the VPR and the Multiple Opening and Closing Nets and Environmental Sensing System (MOCNESS, Wiebe et al. 1976), Broughton and Lough (2006) reported that the VPR estimated ca. twice as high abundances as the MOCNESS.

Both the LOPC and the VPR can be used in conjunction with a range of other sensors as integrated packages for mapping 3-dimensional distributions of zooplankton and coupled biological-physical processes in the ocean. This is very promising for the entire field of zooplankton ecology and has the potential to extend the understanding of coupled processes from small- to meso- and large-scales. This progress is dependent on building confidence and competence among users, and in this sense much work is still to be done. Improvement in the performance of biological sampling equipment also depends on the communication between scientist and engineers, so that both groups understand the challenges of design and engineering as well as the quality of the data gathered and the costs of acquiring and using the equipment. The simple and operationally robust OPC system cannot distinguish particles belonging to different functional groups in the sea, which has clouded the reliance on getting correct abundance estimates from the OPC (Heath et al. 1999; Zhang et al. 2000). For instance, the overlap in size between such widely different groups as copepods and marine snow may reduce the overall quality of the information gathered when a separation between these two groups is needed (Herman 1992; Ashjian et al. 2005). The LOPC gathers not only data on the size of particles, but also allows computation of the particles transparency. This information may be used 
to distinguish between particles that are relatively transparent such as marine snow or hydrozoans, and more opaque particles such as copepods (Checkley et al. 2008; Gaardsted et al. 2010). Furthermore, the LOPC has a better resolution than the OPC, the problem of coincident counts is thus diminished (Herman et al. 2004). The VPR, on the other hand, collects images of relatively high taxonomic resolution, which gives access to more qualitative aspects of particles. The image data collected by the VPR require more storage space and post-processing is more time-consuming compared to the data collected by the LOPC.

The objective of this study is to compare the overall ability of the LOPC and the VPR to quantitatively estimate abundances of Calanus finmarchicus using data collected during an early summer situation in two North Norwegian fjords. A combined set-up of both instruments was tested in a range of situations with different levels of fluorescence, marine snow, and of Calanus sp.. In addition, this study provides a valuable insight into the design of analysis and choices taken during the post-processing of primary data.

\section{Methods}

\subsection{Field sampling}

Data were collected at 9 stations in two North Norwegian fjords, Andfjorden and Vågsfjorden, during a cruise with R/V "Johan Ruud” from 16-20 June 2008 (Fig. 1). Initially, in each fjord a tow of an instrument platform (Scanfish; GMI, Denmark) was performed along a transect from the mouth of the fjord towards its inner part. The Scanfish was equipped with a CTD-F (CTD: SBE 911plus, Seabird Electronics Inc., USA; F: Seapoint Chlorophyll Fluorometer, Seapoint Sensors Inc., USA) and a LOPC (Brooke Ocean Technology Ltd., Canada). Then, based on the data from these instruments, the positions of stations were selected in order to cover a range of situations as diverse as possible with respect to fluorescence and zooplankton abundance. At each station between 6 and 28 (usually 15) vertical profiles were sampled from the surface to $100 \mathrm{~m}$ depth by LOPC, CTD-F and autonomous, digital VPR (Seascan Inc., USA) equipped with a Uniq B/W 1.4 
MegaPixel camera and an additional CTD-F (CTD: Seabird SBE49, "Fastcat", Seabird Electronics Inc., USA; F: ECO Puck chlorophyll $a$ fluorometer, WET labs Inc., USA). The LOPC was mounted on the VPR frame to ensure that the sampling volumes of the two instruments overlapped. It must be pointed out that the sampling volumes of the LOPC and VPR did not completely overlap, nor were they of equal size or shape, such that the instruments were unable to detect exactly the same particles. Moreover, the combined sampling platform operated in a different manner than the individual instruments, with respect to orientation in the water and flow patterns around the sensors. Only data from the profiles collected during the down-casts were used for analysis, because these had an unobstructed water flow. The instrument setup was lowered at a speed between 0.7 and $0.8 \mathrm{~m} \mathrm{~s}^{-1}$. During the casts, the LOPC logged data with a frequency of $2 \mathrm{~Hz}$, the CTD-F with a frequency of $6 \mathrm{~Hz}$, and the VPR and the additional CTD with a frequency of ca. 20 and $16 \mathrm{~Hz}$, respectively. Additional data were collected at two stations (A and I, Fig. 1), one in each fjord, to aid interpretation of the LOPC- and VPR-data. At these stations, discrete water samples and stratified zooplankton net samples were collected by 5L-Niskin bottles and by vertical Multinet (Hydrobios, Kiel, Germany) tows (180 $\mu \mathrm{m}$ mesh width, $0.25 \mathrm{~m}^{2}$ mouth opening), respectively. Water samples were obtained from the upper mixed layer, i.e. from 5, 15 and $30 \mathrm{~m}$ in Andfjorden, and from 5, 15 and $40 \mathrm{~m}$ in Vågsfjorden. On board, water samples were preserved in a solution of $2 \%$ formaldehyde (buffered with hexamine) in seawater. Zooplankton samples were taken from the upper $100 \mathrm{~m}$ in discrete intervals (100-75-50-25-15-0 m) and were preserved in a solution of 20 $\%$ fixation agent (50\% formaldehyde buffered with hexamine, $50 \% 1,2$ propandiol) in seawater.

\subsection{Analysis of water and net samples}

From the water samples, aliquots of $2 \mathrm{ml}$ were analysed for phytoplankton and microzooplankton genera, and if possible species. Cells were identified and enumerated applying an inverted Leitz microscope with 40x magnification. From each sample a minimum of 100 cells were counted. 
Zooplankton net samples were split into equal parts using a Motoda plankton splitter. Splitting was continued until a subsample contained less than an estimate of 300 Calanus sp.. From the subsample, zooplankton species were identified and enumerated under a stereomicroscope. Developmental stages were assigned to individuals of Calanus spp. and Metridia spp.. If the subsample contained less than 200 Calanus sp., an additional subsample was analysed. Abundances were calculated based on filtered water volume, which was obtained from the flowmeters of the Multinet.

\subsection{Analysis of LOPC data}

The LOPC counts and measures particles that pass through a laser beam inside the instrument as the LOPC is lowered through the water column (Herman et al. 2004). The laser light beam is emitted from one side of the sampling channel and is received by an array of diodes on the other side. Two different types of particles are registered by the instrument: Particles that occlude only 1 to 2 diodes are termed Single Element Particles (SEP), and their size is returned directly as equivalent spherical diameter (ESD). Particles that cover more than 2 diodes are termed Multi Element Particles (MEP), and their size is returned as a digital size, which is then converted into ESD by the user. The ESD is a quantity that yields the diameter that a particle had if it were an opaque sphere; it is thus a property describing the size of a particle as well as indicating its transparency. We calculated the ESD as described in the LOPC manual (Anonymous 2006). Below ca. $0.8 \mathrm{~mm}$ ESD typically SEPs outnumber MEPs, while above ca. $0.8 \mathrm{~mm}$ ESD few SEPs are observed and the size spectrum is then dominated by MEPs. In addition to size, for the MEPs also information on the light received by each diode is logged. Based on this, the transparency of each MEP can be estimated. All LOPC data were analysed using especially developed scripts in the python programming language (version 2.6.2).

An effort has been made to distinguish copepods from other particles, in particular marine aggregates, which may fall into the same size range as the target species. It has been proposed that copepods are more opaque than marine aggregates or gelatinous zooplankton Checkley et al. (2008). Based on the light information returned by the 
LOPC for the MEPs, we therefore analysed the transparency of MEPs by computing an attenuation index $(\mathrm{AI})$ as

$$
A I=\operatorname{mean}\left(\sum_{n=2}^{n-1} D S_{M E P_{n}}\right) / \max D S
$$

where $\max D S$ is the complete occlusion of one diode, i.e. the maximal digital size $(D S)$ one element $(n)$ of the MEP could have, and mean $\left(\sum_{n=2}^{n-1} D S_{M E P_{n}}\right)$ is the mean $D S$ of all elements of the MEP apart from the first and the last element. The first and the last element were not included in computing the mean $D S$, because the elements at the edge of a MEP may only partly cover the area of a diode, which could then result in a low $D S$ despite high opacity of the element. In this respect the AI computed here differs from the one computed by Checkley et al. (2008), but we followed his example otherwise.

To determine abundance of Calanus finmarchicus CIV-CVI obtained from the LOPC, we needed to select a size range in which $C$. finmarchicus clearly dominates, or in which it is the only species. This task is facilitated by the larger size of older developmental stages of $C$. finmarchicus relative to most other pelagic copepods in the Subarctic, and by the often clearly dominating role of $C$. finmarchicus in subarctic meso-zooplankton communities. To prevent non-copepod particles being counted as C. finmarchicus, we analysed the distribution of MEPs in relation to their AI (Fig. 2, left). Following this, we excluded all MEPs that were quite transparent $(\mathrm{AI}<0.4)$ when computing abundance of $C$. finmarchicus. Nevertheless, determining the size range will always be somewhat subjective, because most of the times a few other zooplankton individuals will fall into the size range selected for $C$. finmarchicus. Based on earlier calibrations of the Optical Plankton Counter (OPC) (Heath et al. 1999; Edvardsen et al. 2002; Baumgartner 2003; Basedow et al. 2006), recent studies employing the LOPC have used the size ranges of 1.2-2.0 mm ESD (Herman and Harvey 2006), 1.1-1.7 mm ESD (Checkley et al. 2008) and 1.0-2.0 mm ESD (Basedow et al. 2010) to analyse abundance of Calanus spp. CIV-CVI. A recent calibration of the LOPC for overwintering $C$. finmarchicus, used a size range of 0.9-1.5 mm ESD for the whole mesozooplankton community in which $C$. finmarchicus CIV-CVI made up ca. $85 \%$ (Gaardsted et al. 2010). Here, we chose to use a size range of 1.0-2.0 mm, based on the mean size distribution of particles at all stations and on 
the spectrum at station $\mathrm{G}$, where $C$. finmarchicus was very abundant (Fig. 3). On the one hand, this size range will exclude Calanus individuals at the edges of the size distribution, but on the other hand it minimises the overlap of other copepods into the size range determined for CIV-CVI C. finmarchicus.

\subsection{Analysis of VPR data}

The VPR was used with the low magnification setting S2 (22 x $32.5 \mathrm{~mm}$ window), which gave a $24 \mathrm{ml}$ factory-calibrated sampling volume (Seascan, Inc., USA) at the chosen extraction parameters. Because the factory calibration is made using a plastic grid, we also made a laboratory assay with live copepods, which agreed with the factory estimate. The S2 magnification has proven to be the most effective setting for Calanus sp. and other medium-sized mesozooplankton during previous studies in Norwegian coastal waters (Norrbin et al. 2009). Image files and environmental data were collected in a compressed file on a resident hard drive and later downloaded to shipboard computers and decompressed using the Autodeck software (Seascan, Inc., USA). This program extracts regions of interest (rois) containing time-labelled, in-focus objects, and environmental data. The latter, including sampling time and CTD-F data, were accessed using the Visual Plankton package (C. S. Davis, WHOI, USA).

Rois thumbnails were sorted manually into taxonomic groups; e.g. Calanus sp., small decapods, appendicularians, pteropods, polychaetes, hydromedusae, ctenophores, smaller copepods and marine snow. Rois also revealed abundant air bubbles in surface waters. The individual sightings were processed and analysed using our own Matlab scripts (Release 14, The MathWorks, Inc., U.S.A). Identified taxa were binned into $5 \mathrm{~m}$ bins, and abundance per $\mathrm{m}^{3}$ was calculated for each depth interval.

\subsection{Comparison of LOPC and VPR}

To compare abundance estimates from the LOPC and the VPR, we used the mean abundances of $C$. finmarchicus CIV-CVI that were collected in each depth bin and at each station by the two instruments and fitted a linear regression line to a scatterplot of the 
data by the method of least-squares.

At each station, we compared the vertical profiles of abundance of CIV-CVI Calanus finmarchicus obtained from the LOPC with those obtained from the VPR. We tested if the shapes of the depth profiles of mean abundance from LOPC and VPR, respectively, were the same by applying a modified Kolmogorov-Smirnov statistical test that allows for patchiness of zooplankton distribution when comparing depth profiles (Solow et al. 2000; Beet et al. 2003). The null hypothesis was that mean abundance obtained by the LOPC at each depth is the same constant multiple of mean abundance at the same depth obtained by the VPR (Beet et al. 2003). We performed this test with abundance data binned into 5-, 10- and 15 m-depth bins. The analysis was performed in Matlab (Release 14, The MathWorks, Inc., U.S.A.)

\subsection{The effect of marine snow on zooplankton abundance esti- mates}

We analysed the effect of marine snow on the abundance of different zooplankton size groups. Similar to the comparison of abundance estimates by LOPC and VPR, we fitted a linear regression line to a scatterplot of data on the mean abundance of marine snow (from the VPR) and of zooplankton (from the LOPC) in each depth interval and at each station. This regression analysis was performed for the size groups 0.25-0.5, 0.5-0.75, 0.75-1.0, and 1.0-2.0 mm ESD. For the size group 1.0-2.0 $\mathrm{mm}$ ESD we also tested if there was a correlation when particles with an $\mathrm{AI}<0.4$ were excluded.

\section{Results}

\subsection{Situation in the fjords}

Both fjords were filled with the Norwegian coastal water, and the water column was stratified with a pycnocline at $20 \mathrm{~m}$ in Andfjorden and $15 \mathrm{~m}$ in Vågsfjorden (data not shown). Temperatures ranged from $4.8^{\circ} \mathrm{C}$ at $100 \mathrm{~m}$ to $8{ }^{\circ} \mathrm{C}$ in surfaces waters. Salinity 
values were between 33.0 at surface and 34.2 at $100 \mathrm{~m}$.

Fluorescence in both fjords was highest in the upper 30 to $40 \mathrm{~m}$ and very low below this depth (data not shown). In Andfjorden, the highest fluorescence was observed close to the mouth of the fjord, where stations D, E and F were placed. At station F, a subsurface maximum of fluorescence was observed at $30 \mathrm{~m}$, while at stations D and E fluorescence was distributed relatively homogeneously in the upper $30 \mathrm{~m}$. In Vågsfjorden, fluorescence was higher at the mouth of the fjord (Station I) and in the inner part (Station G) compared to the centre parts of the transect (Station H). Throughout the fjord, subsurface maxima of fluorescence were observed between 15 and $25 \mathrm{~m}$.

The phytoplankton community at the two stations sampled was characterised by low cell numbers. Only small amounts $\left(<50\right.$ cells $\left.\mathrm{L}^{-1}\right)$ of Phaeocystis pouchetii solitary cells and no colonies occurred at both stations. In addition, marginal amounts $\left(<5\right.$ cells $\left.\mathrm{L}^{-1}\right)$ of diatoms were observed at $15 \mathrm{~m}$ in the inner part of Andfjorden.

The distribution of older developmental stages of Calanus sp. as observed by the LOPC mounted on the Scanfish, differed markedly between Andfjorden and Vågsfjorden (data not shown). While highest abundances (up to 5000 ind. $\mathrm{m}^{-3}$ ) were observed in the upper $25 \mathrm{~m}$ in Andfjorden, most Calanus sp. (up to $2500 \mathrm{~m}^{-3}$ ) were observed below $20 \mathrm{~m}$ in Vågsfjorden. Only at the mouth of Vågsfjorden, where station I was located, the highest abundances (500 ind. $\mathrm{m}^{-3}$ ) of Calanus sp. were observed in the upper $20 \mathrm{~m}$ as in Andfjorden. In the inner part of Vågsfjorden at station G, high abundances were observed down to $80 \mathrm{~m}$.

The mesozooplankton community at station A in Andfjorden was dominated by the small copepod Oithona similis (607 ind. $\mathrm{m}^{-2}$ ), copepod (68 ind. $\mathrm{m}^{-2}$ ) and cirriped (42 ind. $\mathrm{m}^{-2}$ ) nauplii, and older developmental stages of Calanus finmarchicus (113 ind. $\mathrm{m}^{-2}$ ). Also in Vågsfjorden, at station I, O. similis and C. finmarchicus were among the dominant mesozooplankton species, but abundances here were an order of magnitude higher than those of station A. In addition to cirriped nauplii (108 ind. $\mathrm{m}^{-2}$ ), juvenile bivalves had high abundances (1637 ind. $\mathrm{m}^{-2}$ ) at station I. Metridia spp., Pseudocalanus spp. and Microcalanus spp. occurred in low abundances $\left(<40\right.$ ind. $\left.\mathrm{m}^{-2}\right)$ in both fjords. 
Few jellyfish $\left(<3\right.$ ind. $\left.\mathrm{m}^{-2}\right)$ and no appendicularians were observed by the Multinet sampling at either station.

\subsection{Comparing C. finmarchicus abundances obtained by Multi- net, LOPC and VPR}

Abundances from the Multinet, the LOPC and the VPR were in the same order of magnitude (Table 1). However, the Multinet was deployed separately from the LOPC-VPR setup, so that Multinet samples were obtained from a slightly different position and time. Furthermore, both the LOPC and the VPR data showed a high standard deviation between consecutive profiles, indicating a very patchy distribution of zooplankton. Precise correspondences between samples were thus not to be expected. Mean abundances obtained by the VPR were about twice as high as those obtained from the LOPC, but they showed the same tendencies as both the Multinet and the LOPC (Table 1).

The abundance of $C$. finmarchicus CIV-CVI estimated by the LOPC was strongly correlated to the abundance estimated by the VPR (Fig. 4). However, at abundances lower than ca. 200 individuals $\mathrm{m}^{-3}$ there was a large spread in the data obtained from both instruments (Fig. 4). Furthermore, mean abundances obtained from the LOPC were lower by a factor of two compared to those estimated by the VPR. Similar results were obtained when performing regression analyses between both instruments based on different size ranges chosen for the LOPC. In addition to the size range applied in our study, we applied three different size ranges from recent studies analysing abundance of C. finmarchicus (Herman and Harvey 2006; Checkley et al. 2008; Gaardsted et al. 2010). All size ranges from the literature resulted in lower estimates of $C$. finmarchicus CIV-CVI abundances compared to this study, and thus in a higher discrepancy between abundance estimates from the VPR and LOPC (data not shown). 


\subsection{Comparing vertical profiles of $C$. finmarchicus abundance obtained by LOPC and by VPR}

Visually, the profiles of abundance obtained from the LOPC and VPR resembled each other closely at all stations (three stations are shown in Fig. 5). There were no significant statistical differences (at a significance level of $p=0.01$ ) at three stations, when abundance data were binned into 5 m-depth bins (Table 2). When data were binned into $10 \mathrm{~m}$-depth bins, only two out of nine stations were significantly different, and at $15 \mathrm{~m}$ depth binning there was no difference between profiles obtained from the two instruments at any of the stations. Two stations would have been different at a significance level of $p=0.02$, even when binning abundance data into $15 \mathrm{~m}$-depth bins. These were the two stations (A and D) where mean abundance of $C$. finmarchicus in the water column was lowest (Table 2).

\subsection{Correlation between marine snow and particle counts by the $\mathrm{LOPC}$ in different size ranges}

Up to 1000 particles $\mathrm{m}^{-3}$ of marine snow were observed in the fjords (Fig. 6). The abundance of any size group of zooplankton was only weakly correlated to the abundance of marine snow; coefficients of determination $\left(r^{2}\right)$ were $<0.2$ for all size groups (Table 3 ). The slope of the linear regression lines, however, was significantly $(p=0.05)$ different from 0 (Table 3). A weak positive correlation was observed for zooplankton smaller than $0.75 \mathrm{~mm}$ ESD. For the zooplankton size groups larger than $0.75 \mathrm{~mm}$ ESD, there was a weak negative correlation between abundance of zooplankton and abundance of marine snow.

\section{Discussion}

The vertical profiles of $C$. finmarchicus CIV-CVI abundance obtained by LOPC and VPR showed a striking similarity. The observed patterns of distribution were virtually identical 
at all stations sampled in the two northern Norwegian fjords. Abundance estimates of C. finmarchicus CIV-CVI by both instruments, however, differed. In spite of that, when binning data into $15 \mathrm{~m}$ depth-bins, no significant differences between instruments were observed at any station due to the very high standard deviation between consecutive profiles. That is, the difference in abundance between consecutive profiles was higher than the difference in abundance measured by the LOPC and by the VPR, respectively. The water volume sampled by both the LOPC and the VPR is relatively small, which is likely responsible in part for the large standard deviation between consecutive profiles. The opening of the LOPC is $7 \times 7 \mathrm{~cm}$ or $0.0049 \mathrm{~m}^{2}$; in a $5 \mathrm{~m}$-depth interval therefore 24.5 L are sampled. The VPR takes ca. 20 pictures per second, each "sampling" a volume of $24 \mathrm{ml}$. At a tow speed of $0.8 \mathrm{~m} \mathrm{~s}^{-1}, 125$ pictures are taken in a $5 \mathrm{~m}$-depth bin, yielding a sampling volume of $3 \mathrm{~L}$. These small sampling volumes, especially of the VPR, make abundance estimates less accurate when zooplankton abundance in the water column is low. The significant differences that were observed between profiles sampled by the two instruments at stations where abundance was low $\left(<100\right.$ individuals $\left.\mathrm{m}^{-3}\right)$, and when data were binned into $5 \mathrm{~m}$ - or $10 \mathrm{~m}$-depth bins, can therefore be explained by the small sampling volumes of the VPR and LOPC. At stations with higher abundances, the likelihood of obtaining accurate abundance estimates based on small sampling volumes increases, and in this study no significant differences between the VPR and LOPC were observed at stations with abundances $>100$ individuals $\mathrm{m}^{-3}$, when data where binned into $5 \mathrm{~m}$ - or $10 \mathrm{~m}$-depth bins.

Nevertheless, the Calanus finmarchicus CIV-CVI abundances estimated by the VPR were about twice as high as those estimated by the LOPC. Apart from the small sampling volume other uncertainties are associated with both instruments. For the VPR, only particles that are in focus should be counted to correctly estimate numbers in the sampling volume. It is not always straightforward, however, to decide which particles are in focus and which are too blurred to be counted. Depending on the decision made by the analyser, numbers could be over- or underestimated, and the effect on estimated abundances could be quite substantial because of the small sampling volume of the VPR. For the LOPC, the 
analyser has to decide on a size range to apply to the data in order to estimate abundance of target species. This procedure intends to minimise interference of other, co-occurring species, which have a size range that partly overlaps with the size range of the target species. In the case of older developmental stages of Calanus spp., most co-occurring species of quantitative importance are smaller, and therefore the size range is usually cut below 1.2 or $1.0 \mathrm{~mm}$ (Herman and Harvey 2006; Checkley et al. 2008; Basedow et al. 2010). Depending on the positioning of a zooplankton particle in the LOPC channel, size will vary substantially even within one species and developmental stage. For example, those copepods that enter the LOPC channel such that they are positioned with head and urosome directly in line between laser and diode, will be registered with a small size by the LOPC. These individuals will therefore be missed when truncating the size range at a lower limit.

We excluded particles with an attenuation index $<0.4$ to make sure that we only counted copepods and no transparent particles, which could be non-zooplankton particles like marine snow. The distribution of these more transparent particles, however, showed the same pattern as "Calanus"-particles, i.e. particles between 1 and $2 \mathrm{~mm} \mathrm{ESD} \mathrm{and}$ with an AI $>0.4$ (see Fig. 5). Distribution patterns of marine snow determined from the VPR, on the other hand, showed an inverse pattern to the Calanus sp. distribution. Checkley et al. (2008) defined particles with an AI >0.6 as Calanus-particles in surface waters off the Californian coast in September, while Gaardsted et al. (2010) observed AI distributions centred around 0.3 and 0.4, respectively, for Calanus spp. in the laboratory and at depth in overwintering habitats in January. We observed a distribution where most particles had an AI $<0.2$. Those with an AI $>0.2$ showed a Gaussian distribution centred around 0.65. Also in the size range determined for Calanus sp., the particles ranged from very transparent $(\mathrm{AI}<0.2)$ to quite opaque $(\mathrm{AI}>0.8)$, but those particles that were more opaque $(\mathrm{AI}>0.4)$ dominated.

Density of marine snow was very weakly and slightly negatively correlated to abundance of Calanus sp. in our study. We can therefore say with great certainty that the relatively transparent particles in the size range of Calanus sp. were not marine snow. 
The colouration of Calanus spp. can change considerably depending on gut content, pigmentation of the antennae and lipid content. It is therefore not surprising to see a range in transparency from nearly translucent to quite opaque individuals in Calanus. Transparency is also likely to vary with season, and the most opaque copepods might be those lipid-rich individuals found in surface waters just before descending to overwintering habitats. The relatively high AIs reported by Checkley et al. (2008) may thus indicate lipid-rich individuals, while the relatively low AIs reported by Gaardsted et al. (2010) may indicate that copepods had mostly used up their lipid reserves in January. In our case, i.e. a summer situation where copepods were feeding and accumulating lipids, it might have been better to include all particles, or at least all particles with an AI $>0.2$, to determine abundance of Calanus. When including the more transparent particles within the size range of $C$. finmarchicus, LOPC abundance estimates were slightly higher and therefore closer to those abundances obtained by the VPR (Fig. 5). Adding up also those Calanus particles below the size range applied here is practically difficult due to high numbers of smaller copepods in this size range. If one succeeded, one might not arrive at the exact same abundances as estimated by the VPR, but it would certainly further decrease the discrepancy between LOPC and VPR.

Compared to the Multinet, the LOPC showed a close agreement in abundance estimates of Calanus sp. whereas the VPR may have overestimated abundances. Abundance estimates based on sampling with zooplankton nets are strongly dependent on the mesh size of the net (Nichols and Thompson 1991). With most mesh sizes only 2 to 4 copepodite stages of the target species are sampled quantitatively (Nichols and Thompson 1991; Gallienne and Robins 2001; Hopcroft 2002). Yet, the usual way to calibrate optical plankton counters has been to tune the size range such that estimated abundances most closely resemble abundances estimated by a net equipped with one mesh size only (e.g. Heath et al. 1999; Gaardsted et al. 2010). Based on the data presented in this study, we think this approach needs to be reconsidered. Baumgartner (2003) used a calibration equation based on net data to estimate $C$. finmarchicus abundance from the OPC. His abundance estimates compared well with abundances estimated by a VPR, but regrettably no details 
on the post-processing of the OPC data were given in that study (Baumgartner et al. 2011). The VPR might be a preferred instrument to groundtruth measurements of a LOPC, because "what you see is what you get", such that the researcher can be sure that only the target species and no marine snow is counted.

During this study few autotrophs were observed and no colonies of Phaeocystis sp.. Marine snow occurred at densities of up to 1000 particles $\mathrm{m}^{-3}$, and did not contribute to the amount of particles in the size range of Calanus sp.. Densities of marine snow were only weakly correlated also to other size ranges of particles. The strongest correlations, albeit still very weak $\left(r^{2}=0.13\right.$ and 0.16$)$, were observed with the two smallest size groups (0.25-0.5 and 0.5-0.75 $\mathrm{mm}$ ESD), and these were the only correlations where the regression line had a positive slope. Moreover, most of the particles with an AI $<0.2$ were smaller than $0.75 \mathrm{~mm}$ ESD. When analysing abundance of small copepods therefore the concept of excluding particles with small AIs may prove to be more fruitful. One has to keep in mind, however, that the information on the transparency of particles is only available for multi-element-particles (MEPs, see Methods for an explanation), whereas single element particles (SEPs) typically outnumber MEPs below ca. 0.8 mm ESD. Our results from the relatively low turbidity in northern Norwegian fjords are in line with the results of a study from waters off the Brazilian coast, where the LOPC was compared to the ZooScan (Grosjean et al. 2004) and was found to yield reliable data for all but those stations with visible turbid waters close to the coast (Schultes and Lopes 2009).

Tuning LOPC abundance estimates to those of the VPR is not advisable, because both instruments require certain decisions to be made during post-processing, which will influence abundance estimates. Even so, in this study no ecological meaningful differences were observed between vertical distribution patterns of Calanus sp. CV observed by the VPR and the LOPC, respectively. Because of the small sampling volume of both instruments, it is important to take enough replicate measurements, especially at low abundances (cf. Davis et al. 2005), to ensure statistically meaningful results. In light of the results presented here, we think that the time is now mature for a more extensive use of optical instruments to investigate zooplankton abundance and spatial distributions in 
the sea.

\section{${ }_{437} 5$ Acknowledgements}

We thank the crew onboard R/V "Johan Ruud", and J.-T. Eilertsen and R. Buvang for excellent technical assistance prior to and during the cruise. Special thanks go to H.-C. Eilertsen for the analysis of phytoplankton samples and to M. Daase for the analysis of zooplankton samples. This study was funded by the Norwegian Research Council (NRC) through the project "Harvesting at lower trophic levels - stock assessment and ecological consequences" (project no. 178447/S40). S. Basedow was financed by the NRC through the IPY project "Norwegian Component of the Ecosystem Studies of Subarctic and Arctic Regions" (project no. 76057/S30). F. Norrbin was supported by the NRC project "The significance of thin layers in aquatic plankton communities" (project no. 166781). 


\section{References}

Anonymous, 2006. LOPC Software Operation Manual. Brooke Ocean Technology Ltd., Dartmouth, Nova Scotia, Canada.

Ashjian, C. J., Davis, C. S., Gallager, S. M., Alatalo, P., 2001. Distribution of plankton, particles, and hydrographic features across Georges Bank described using the Video Plankton Recorder. Deep Sea Research Part II 48, 245-282.

Ashjian, C. J., Davis, C. S., Gallager, S. M., Wiebe, P. H., Lawson, G. L., 2008. Distribution of larval krill and zooplankton in association with hydrography in Marguerite Bay, Antarctic Peninsula, in austral fall and winter 2001 described using the Video Plankton Recorder. Deep Sea Research Part II 55, 455-471.

Ashjian, C. J., Gallager, S. M., Plourde, S., 2005. Transport of plankton and particles between the Chukchi and Beaufort Seas during summer 2002, described using a Video Plankton Recorder. Deep Sea Research Part II 52, 3259-3280.

Basedow, S. L., Edvardsen, A., Tande, K. S., 2006. Spatial patterns of surface blooms and recruitment dynamics of Calanus finmarchicus in the NE Norwegian Sea. Journal of Plankton Research 28, 1181-1190.

Basedow, S. L., Tande, K. S., Zhou, M., 2010. Biovolume spectrum theories applied: spatial patterns of trophic levels within a mesozooplankton community at the polar front. Journal of Plankton Research 32, 1105-1119.

Baumgartner, M., Lysiak, N. S. J., Schuman, C., Urban-Rich, J., Wenzel, F. W., 2011. Diel vertical migration behavior of Calanus finmarchicus and its influence on right and sei whale occurrence. Marine Ecology Progress Series 423, 167-184.

Baumgartner, M. F., 2003. Comparisons of Calanus finmarchicus fifth copepodite abundance estimates from nets and an optical plankton counter. Journal of Plankton Research 25, 855-868. 
Beet, A., Solow, A. R., Bollens, S. M., 2003. Comparing vertical plankton profiles with replicates. Marine Ecology Progress Series 262, 285-287.

Broughton, E. A., Lough, R. G., 2006. A direct comparison of MOCNESS and Video Plankton Recorder zooplankton abundance estimates: Possible application for augmenting net sampling with video systems. Deep Sea Research Part II 53, 2789-2807.

Checkley, D. M., Davis, R. E., Herman, A. W., Jackson, G. A., Beanlands, B., Regier, L. A., 2008. Assessing plankton and other particles in situ with the SOLOPC. Limnology and Oceanography 53, 2123-2136.

Davis, C. S., Gallager, S. M., Berman, M. S., Haury, L. R., Strickler, J. R., 1992. The Video Plankton Recorder (VPR): design and initial results. Archiv für Hydrobiologie - Beihefte Ergebnisse der Limnologie 36, 67-81.

Davis, C. S., Thwaeites, F. T., Gallager, S. M., Hu, Q., 2005. A three-axis fast-tow digital Video Plankton Recorder for rapid surveys of plankton taxa and hydrography. Limnology and Oceanography: Methods 3, 59-74.

Edvardsen, A., Zhou, M., Tande, K., Zhu, Y., 2002. Zooplankton population dynamics: measuring in situ growth and mortality rates using an Optical Plankton Counter. Marine Ecology Progress Series 227, 205-219.

Gaardsted, F., Tande, K. S., Basedow, S. L., 2010. Measuring copepod abundance in deep-water winter habitats in the NE Norwegian Sea: intercomparison of results from laser optical plankton counter and multinet. Fisheries and Oceanography 19, 480-492.

Gallager, S. M., Davis, C. S., Epstein, A. W., Solow, A., Beardsley, R. C., 1996. Highresolution observations of plankton spatial distributions correlated with hydrography in the Great South Channel, Georges Bank. Deep Sea Researc Part II 43, 1627-1663.

Gallienne, C. P., Robins, D. B., 2001. Is Oithona the most important copepod in the world's oceans? Journal of Plankton Research 23, 1421-1432. 
Grosjean, P., Picheral, M., Warembourg, C., Gorsky, G., 2004. Enumeration, measurement, and identification of net zooplankton samples using the ZOOSCAN digital imaging system. ICES Journal of Marine Science 61, 518-525.

Heath, M. R., 1995. Size spectrum dynamics and the planktonic ecosystem of Loch Linnhe. ICES Journal of Marine Science 52, 627-642.

Heath, M. R., Dunn, J., Fraser, J. G., Hay, S. J., Madden, H., 1999. Field calibration of the Optical Plankton Counter with respect to Calanus finmarchicus. Fisheries and Oceanography 8, 13-24.

Herman, A. W., 1988. Simultaneous measurement of zooplankton and light attenuance with a new Optical Plankton Counter. Continental Shelf Research 8, 205-221.

Herman, A. W., 1992. Design and calibration of a new optical plankton counter capable of sizing small zooplankton. Deep Sea Research Part I 39, 395-415.

Herman, A. W., Beanlands, B., Phillips, E. F., 2004. The next generation of Optical Plankton Counter: the Laser-OPC. Journal of Plankton Research 26 (10), 1135-1145.

Herman, A. W., Cochrane, N. A., Sameoto, D. D., 1993. Detection and abundance estimation of euphausids using an optical plankton counter. Marine Ecology Progress Series 94, 165-173.

Herman, A. W., Harvey, M., 2006. Application of normalized biomass size spectra to laser optical plankton counter net intercomparisons of zooplankton distributions. Journal of Geophysical Reserach 111.

Hopcroft, R. R., 2002. Comparison of plankton size spectra from net tow samples and OPC measurement in Marine Waters. In: Zhou, M., Tande, K. (Eds.), Optical Plankton Counter Workshop. GlOBEC report 17, pp. 7-11.

Hu, Q., Davis, C. S., 2005. Automatic plankton image recognition with co-occurrence matrices and Support Vector Machine. Marine Ecology Progress Series 295, 21-31. 
Nichols, J. H., Thompson, A. B., 1991. Mesh selection of copepodite and nauplius stages of four calanoid copepod species. Journal of Plankton Research 13, 661-671.

Norrbin, F., Eilertsen, H. C., Degerlund, M., 2009. Vertical distribution of primary producers and zooplankton grazers during different phases of the Arctic spring bloom. Deep Sea Research Part II 56, 1945-1958.

Osgood, K. E., Checkley, D. M., 1997. Observations of a deep aggregation of Calanus pacificus in the Santa Barbara Basin. Limnology and Oceanography 42, 997-1001.

Schultes, S., Lopes, R. M., 2009. Laser Optical Plankton counter and Zooscan intercomparison in tropical and subtropical marine ecosystems. Limnology and Oceanography: Methods 7, 771-784.

Solow, A. R., Bollens, S. M., Beet, A., 2000. Comparing two vertical plankton distributions. Limnology and Oceanographpy 45, 506-509.

Sprules, W. G., Jin, E. H., Herman, A. W., Stockwell, J. D., 1998. Calibration of an optical plankton counter for use in freshwater. Limnology and Oceanography 43, 726733.

Wiebe, P. H., Burt, K. H., Boyd, S. H., Morton, A. W., 1976. A mulitple opening/closing net and environmental sensing system for sampling zooplankton. Journal of Marine Research 34, 313-326.

Zhang, X., Roman, M., Sanford, A., Adolf, H., Lascara, C., Burgett, R., 2000. Can an optical plankton counter produce reasonable estimates of zooplankton abundance and biovolume in water with high detritus? Journal of Plankton Research 22, 137-150. 
Table 1: Abundance of Calanus finmarchicus CIV-CVI (individuals $\mathrm{m}^{-3}$ ) as measured by Multinet, Laser Optical Plankton Counter (LOPC) and Video Plankton Recorder (VPR), respectively. Data from LOPC and VPR were collected simultaneously, while there was a time lag between Multinet sampling and sampling with the LOPC-VPR. Only one replicate was obtained by the Multinet, but the LOPC-VPR sampled ca. 15 profiles at each station, and for these instruments abundance \pm standard deviation between profiles is given. LOPC and VPR data were binned in depth intervals matching those intervals sampled by the Multinet.

\begin{tabular}{lcccccc}
\hline & \multicolumn{3}{c}{ Station I - Vågsfjorden } & \multicolumn{3}{c}{ Station A - Andfjorden } \\
\cline { 2 - 7 } Depth $(\mathrm{m})$ & Multinet & LOPC & VPR & Multinet & LOPC & VPR \\
\hline $15-0$ & 728.0 & $507.8 \pm 792.5$ & $1346.6 \pm 1231.3$ & 29.3 & $269.1 \pm 730.6$ & $436.3 \pm 508.8$ \\
$30-15$ & 1109.3 & $1513.9 \pm 1200.9$ & $3929.9 \pm 2079.3$ & 21.3 & $62.7 \pm 225.9$ & $89.8 \pm 163.3$ \\
$50-30$ & 61.3 & $207.2 \pm 354.8$ & $487.7 \pm 466.8$ & 28.6 & $46.4 \pm 192.4$ & $74.4 \pm 159.0$ \\
$75-50$ & 153.6 & $270.6 \pm 381.4$ & $749.0 \pm 456.3$ & 23.0 & $16.1 \pm 115.7$ & $18.4 \pm 59.1$ \\
$100-75$ & 12.4 & $21.7 \pm 108.1$ & $40.7 \pm 109.3$ & 10.9 & $13.7 \pm 106.6$ & $49.4 \pm 120.7$ \\
\hline
\end{tabular}


Table 2: Results of the statistical comparison of depth profiles (downcasts only) of mean abundance of Calanus finmarchicus CIV-CVI obtained from Laser Optical Plankton Counter and Video Plankton Recorder at 9 stations (A-I). 15 to 28 replicate profiles (n) were obtained at each station. The mean abundance (mean abu) in the water column over all replicates and of both instruments is given for comparison. Testing was performed on data binned into 5, 10 and $15 \mathrm{~m}$, respectively, and those bins that resulted in no significant $(p>0.01)$ difference between the profiles obtained from LOPC and VPR, respectively, are marked in bold. B is the value of the test statistic (Beet et al. 2003), and the $p$-value indicates the significance.

\begin{tabular}{|c|c|c|c|c|c|c|c|c|}
\hline \multirow[b]{2}{*}{ Station } & \multirow[b]{2}{*}{$n$} & \multirow[b]{2}{*}{ mean abu } & \multicolumn{2}{|l|}{$5 \mathrm{~m}$} & \multicolumn{2}{|l|}{$10 \mathrm{~m}$} & \multicolumn{2}{|l|}{$15 \mathrm{~m}$} \\
\hline & & & B & $p$ & B & $p$ & B & $p$ \\
\hline $\mathrm{D}$ & 15 & 55.7 & 39.48 & 0.002 & 8.81 & 0.359 & 14.61 & 0.012 \\
\hline $\mathrm{A}$ & 28 & 73.0 & 52.08 & $<0.001$ & 18.64 & 0.017 & 13.53 & 0.019 \\
\hline $\mathrm{F}$ & 16 & 74.8 & 55.11 & $<0.001$ & 23.10 & 0.003 & 3.51 & 0.622 \\
\hline $\mathrm{C}$ & 6 & 76.8 & 41.60 & $<0.001$ & 27.12 & $<0.001$ & 10.97 & 0.052 \\
\hline $\mathrm{E}$ & 15 & 91.6 & 18.60 & 0.352 & 3.13 & 0.926 & 4.86 & 0.433 \\
\hline B & 25 & 405.9 & 45.86 & $<0.001$ & 6.79 & 0.559 & 3.26 & 0.660 \\
\hline I & 16 & 820.6 & 14.84 & 0.607 & 7.25 & 0.510 & 5.606 & 0.347 \\
\hline G & 15 & 870.4 & 19.80 & 0.285 & 10.50 & 0.232 & 6.90 & 0.228 \\
\hline $\mathrm{H}$ & 15 & 1001.7 & 39.94 & 0.001 & 13.67 & 0.091 & 7.63 & 0.178 \\
\hline
\end{tabular}


Table 3: Results of the linear regression analyses comparing data on different size groups of zooplankton obtained from the Laser Optical Plankton Counter against abundance of marine snow obtained from the Video Plankton Counter, see Fig. 6 for a scatterplot of the data.

\begin{tabular}{lrrrr} 
Size groups (ESD) & Intercept & Slope & $r^{2}$ & $p$-value \\
\hline $0.25-0.5 \mathrm{~mm}$ & 9851.1 & 11.06 & 0.129 & $<0.001$ \\
$0.5-0.75 \mathrm{~mm}$ & 304.0 & 0.58 & 0.161 & $<0.001$ \\
$0.75-1.0 \mathrm{~mm}$ & 84.5 & -0.07 & 0.045 & 0.028 \\
$1.0-2.0 \mathrm{~mm}$ & 414.4 & -0.71 & 0.098 & $<0.001$ \\
$1.0-2.0 \mathrm{~mm}, \mathrm{AI}>0.4$ & 325.9 & -0.56 & 0.093 & 0.001 \\
\hline
\end{tabular}




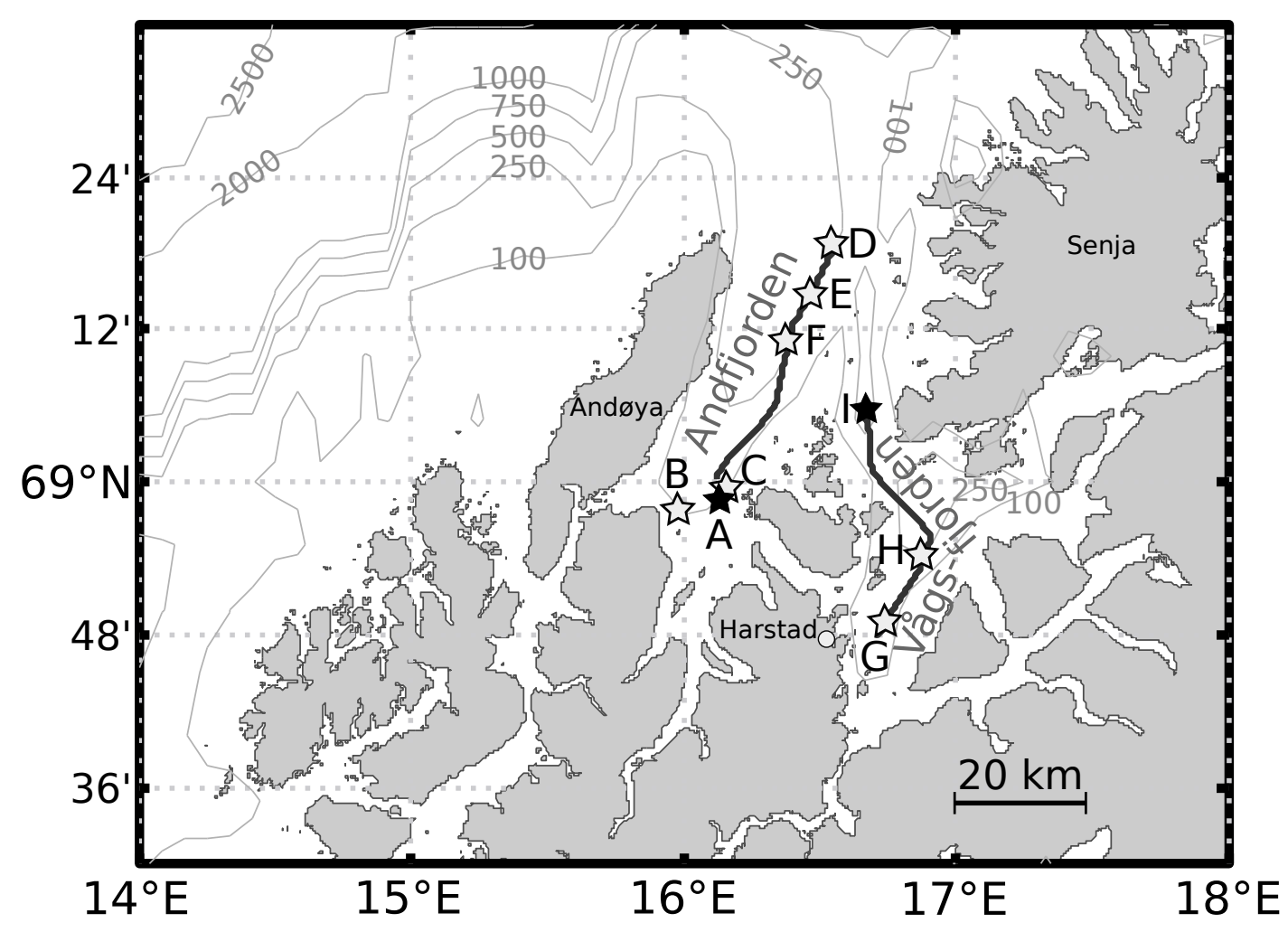

Figure 1: The study area within North Norwegian fjords in June 2008. Transects sampled with the towed instrument platform are shown as black lines. Stations where vertical profiles were obtained from the VPR/LOPC set-up are depicted as grey or black stars (AI), stations where in addition water and net samples for phytoplankton and zooplankton were obtained are depicted with a black star (A and I). 

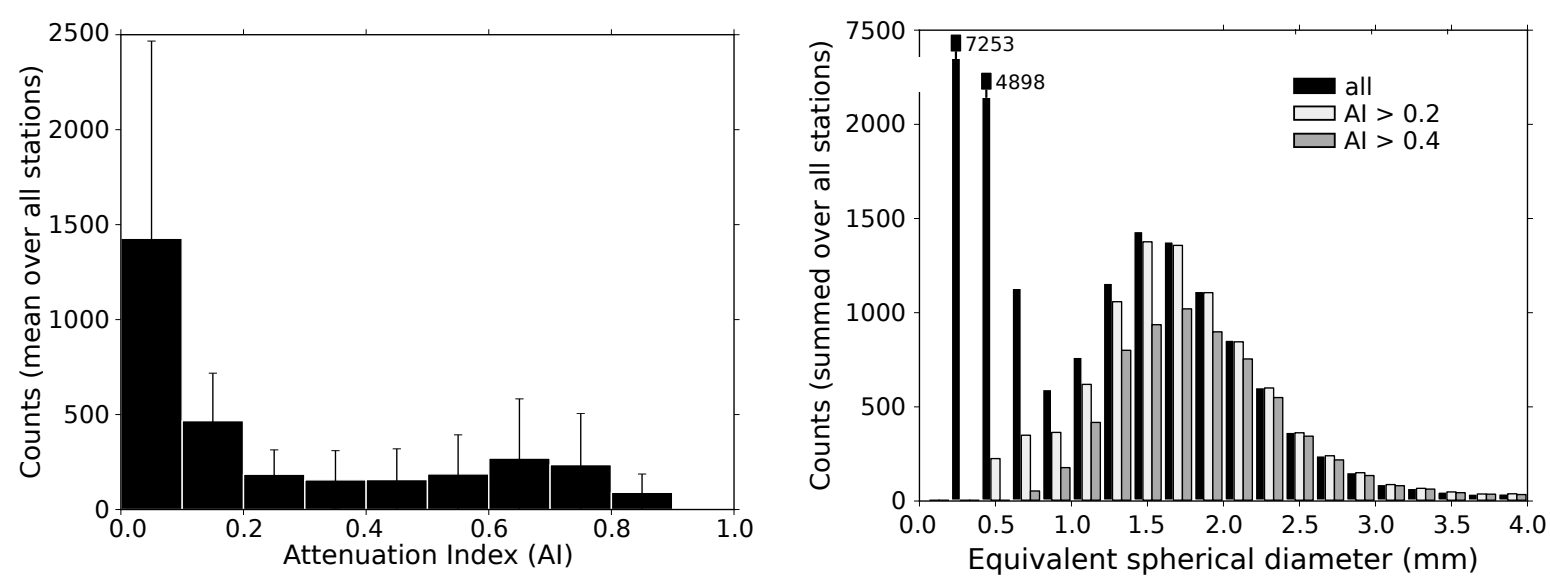

Figure 2: Distribution of Multi Element Particles (MEP) with different transparency. Left: Distribution of all MEPs in relation to their attenuation index (AI). Right: Size distribution of MEPs with different AI, i.e. different transparency. Refer to the methods for the computation of the AI.
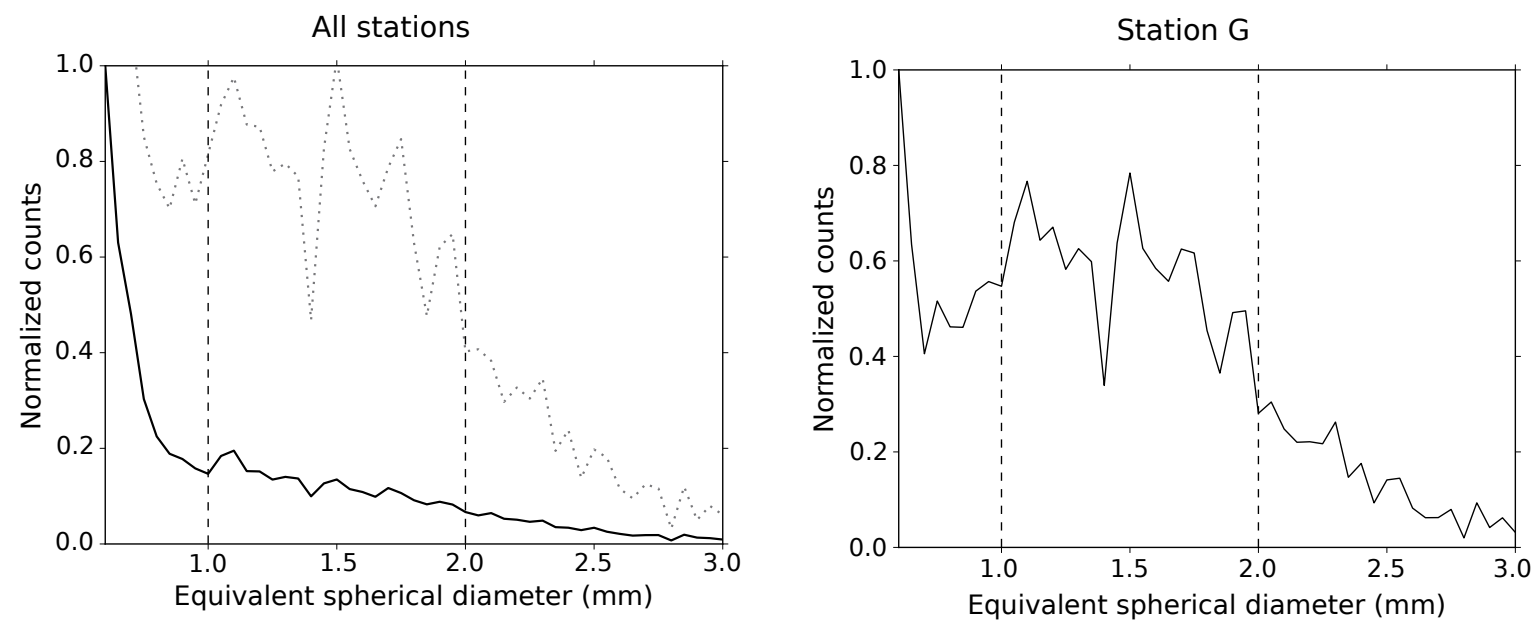

Figure 3: Size distribution of all particles between 0.6 and $3 \mathrm{~mm}$ ESD that were registered by the LOPC in two North Norwegian fjords in June 2008. Left: Size distribution at all stations, the solid line shows the mean over all stations, the dotted line shows the standard deviation between stations. Right: Size distribution at station G, where Calanus finmarchicus was very abundant. The size range applied to estimate abundance of $C$. finmarchicus is denoted by the two dashed vertical lines in both figures. 


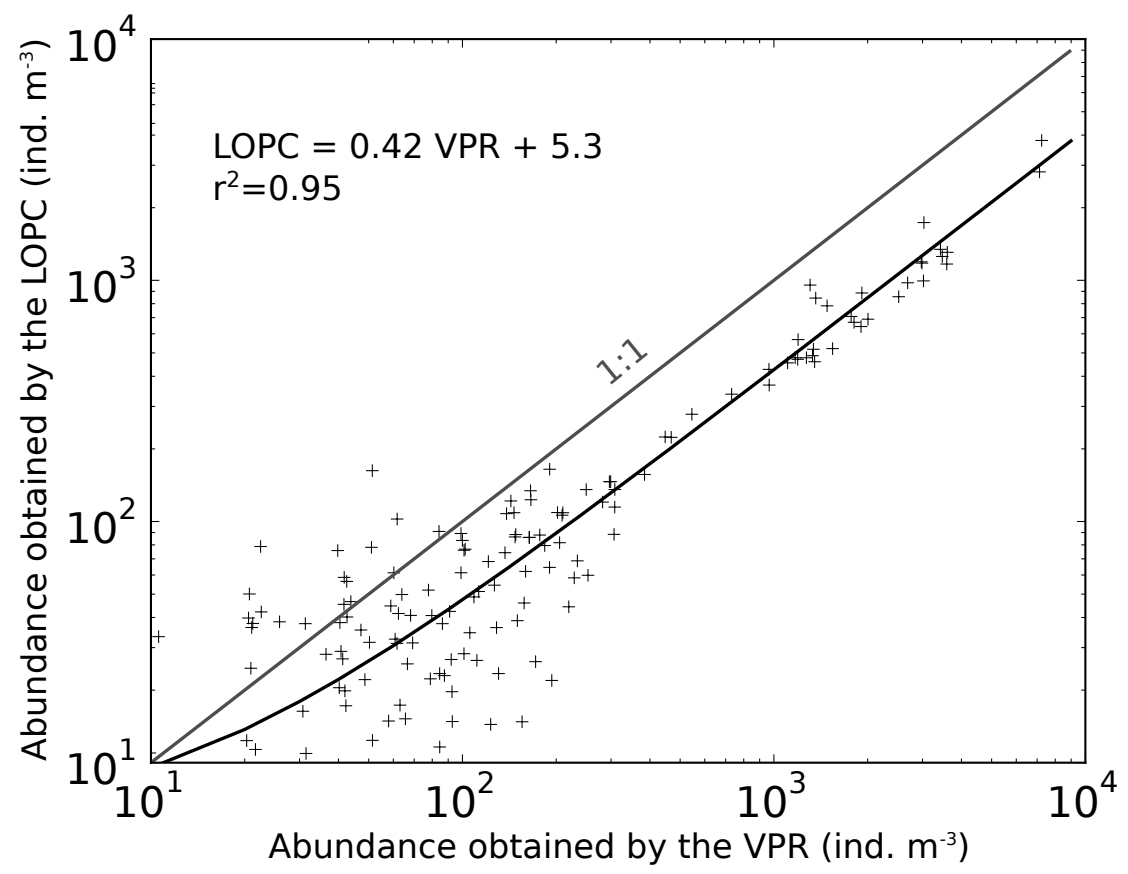

Figure 4: Linear regression analysis of Calanus finmarchicus CIV-CVI abundance estimates from LOPC and VPR, respectively. Note that both axes are logarithmic to span the full range of abundance values. The curvature of the regression line at the lower end is due to the double-logarithmic plot. 


\section{LOPC}

A)

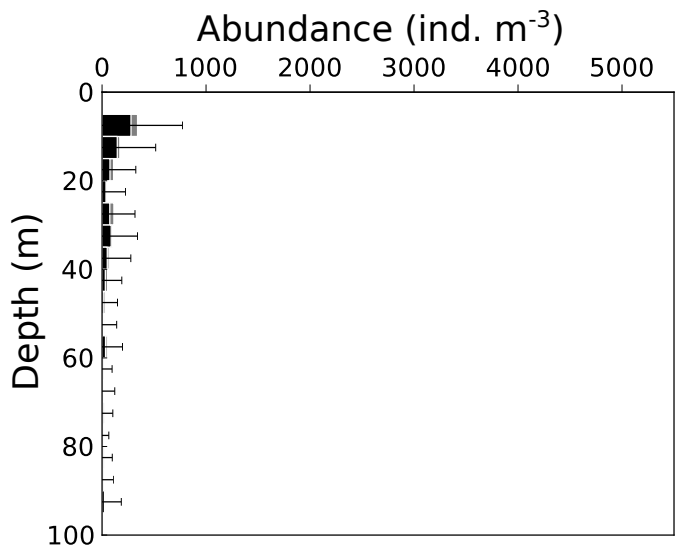

B)

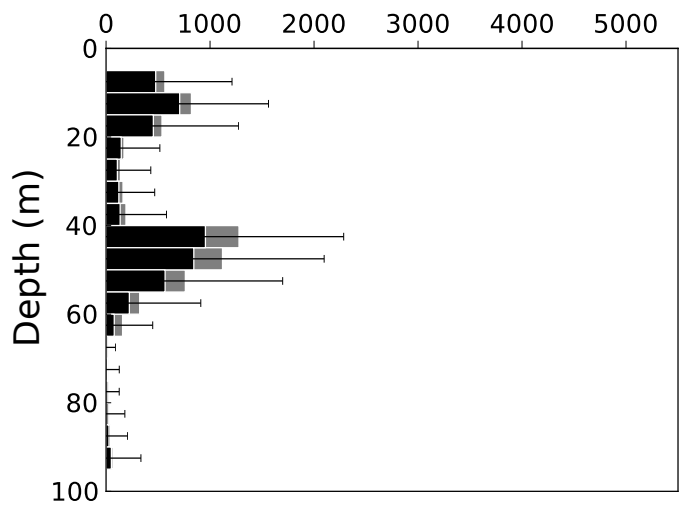

C)

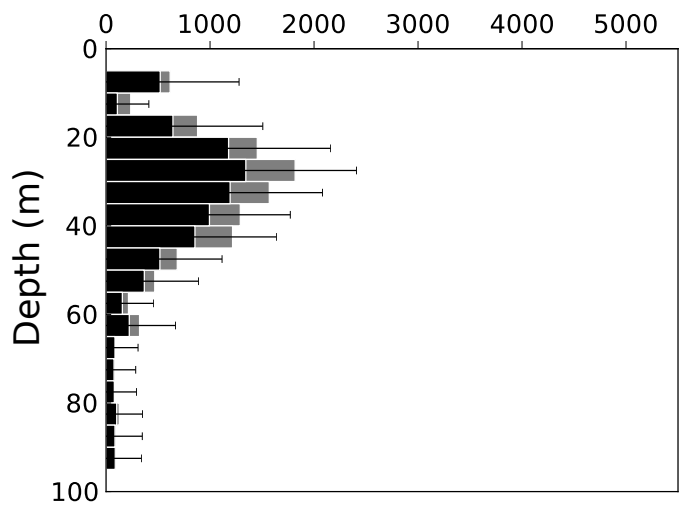

VPR

Abundance (ind. $\mathrm{m}^{-3}$ )
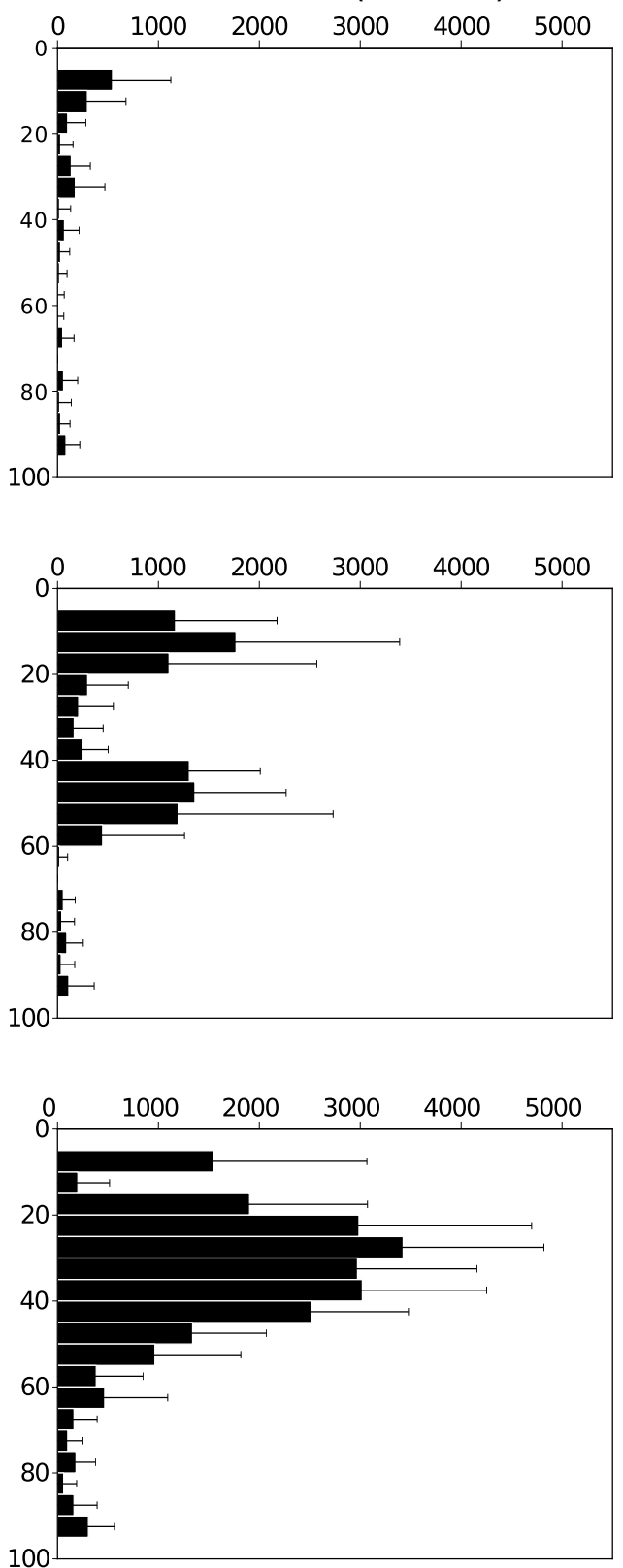

Figure 5: Vertical distribution of Calanus finmarchicus (CIV to adults) at three stations with low, medium and high abundance, respectively, as determined by Laser Optical Plankton Recorder (left) and Video Plankton Recorder (right). A) Station A in Andfjorden, B) Station B in Andfjorden, and C) Station G in Vågsfjorden (Fig. 1). Error bars denote standard deviation between profiles. For the LOPC, abundance of Calanus finmarchicus-particles, i.e. particles within the size range 1-2 $\mathrm{mm}$ and with an attenuation index $(\mathrm{AI})>0.4$, is shown in black. The grey bars indicate more transparent particles $(\mathrm{AI}<0.4)$ within the same size range; these particles are likely also $C$. finmarchicus as is explained in the discussion. 


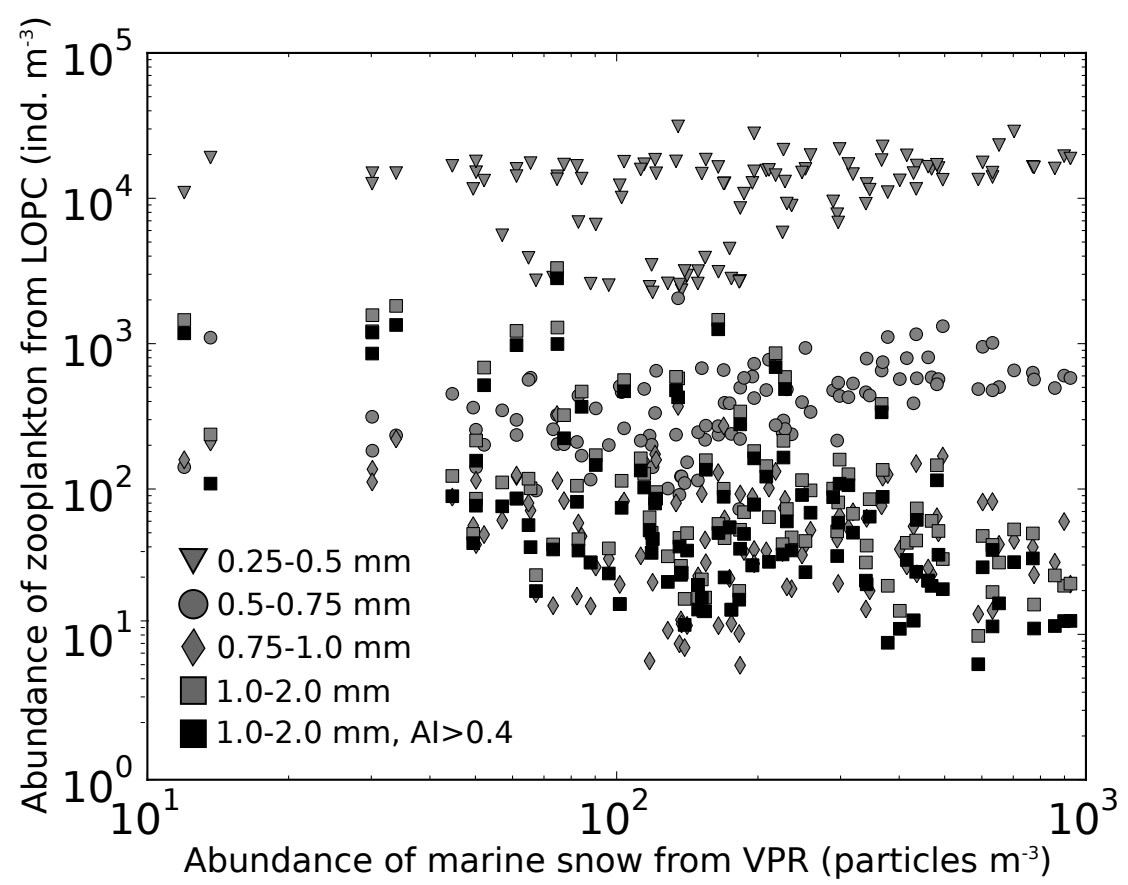

Figure 6: Relationship between mean abundance of zooplankton particles as estimated by the Laser Optical Plankton Counter and mean abundance of marine snow particles as estimated by the Video Plankton Counter. Based on data collected during June 2008 at 6 stations in two northern Norwegian fjords. 